\title{
Improving Order Picking Efficiency with the Use of Cross Aisles and Storage Policies
}

\author{
Charles G. Petersen, Gerald R. Aase \\ College of Business, Northern Illinois University, DeKalb, USA \\ Email: cpetersen@niu.edu
}

How to cite this paper: Petersen, C.G. and Aase, G.R. (2017) Improving Order Picking Efficiency with the Use of Cross Aisles and Storage Policies. Open Journal of Business and Management, 5, 95-104.

http://dx.doi.org/10.4236/ojbm.2017.51009

Received: October 15, 2016

Accepted: December 23, 2016

Published: December 26, 2016

Copyright $\odot 2017$ by authors and Scientific Research Publishing Inc. This work is licensed under the Creative Commons Attribution International License (CC BY 4.0).

http://creativecommons.org/licenses/by/4.0/

\begin{abstract}
Order picking operations need to efficiently process orders in today's competitive environment. Previous research generally assumed on even placement of the cross aisles. This research examines the placement of cross aisles in order picking operations and its effect on various storage policies. While previous research has primarily examined cross aisles and storage policies separately, this research looks at them simultaneously. The results showed no difference between even and uneven placement of cross aisles and that within-aisle storage is better than across-aisle and random storage. The results also showed that within-aisle storage provides greater travel distance savings than the use of cross aisles.
\end{abstract}

\section{Keywords}

Distribution, Warehousing, Order Picking, Cross Aisles, Storage Policies

\section{Introduction}

Order picking is a process of retrieving items or stock-keeping units (SKU) from warehouse storage locations to satisfy customer orders and this process plays an important part in reducing warehousing and supply chain costs. Order picking constitutes $50 \%$ $75 \%$ of the total operating costs for a typical warehouse [1] [2]. Today's warehouse managers are under a lot of pressures due to the global competition and supply chain integration initiatives to decrease order picking time in order to increase the throughput rate and lower operating costs of their operations [3].

Previous order picking research generally focused on one of four main operating policies to improve the performance of the system: picking, routing, storage, and layout. Picking policies involve assigning items or orders to picking tours and include strict-order, batching, and zoning. Routing policies determine the route of a picker for a picking tour and range from simple heuristics to optimal procedures. Storage policies assign SKUs to storage locations. Commonly used storage policies are random storage 
and class-based storage where SKUs are sorted by $\mathrm{ABC}$ analysis into storage classes. Lastly, layout plays an important part in order picking efficiency including the orientation and position of picking and cross aisles.

The focus of this research is to examine the placement of cross aisles. Previous research generally assumes an equal spacing of cross aisles, but has ignored whether unequal placement might reduce picker travel even more. In addition, the authors will evaluate the performance of class-based storage policies relative to random storage with both equally spaced and unequally spaced cross aisles in a manual picking warehouse and the effect of pick list size.

\section{Literature Review}

Order picking has been the topic of much research over the past several decades. The primary focus for most of this research has been identifying more effective picking, storage, routing, and layout policies.

\subsection{Picking}

Picking policies determine where SKUs are placed on a pick list and subsequently retrieved from their storage locations by an order picker. Strict-order picking is a common policy where pickers complete a tour through the warehouse to pick all SKUs for a single order. This policy is often preferred because it is easily implemented and order integrity is always maintained. Combining several orders into batches is an alternative policy that has been shown to reduce total picking time significantly [4] [5] [6] [7]. Zone picking is another policy that divides the warehouse into zones and allows pickers to retrieve SKUs from within a single zone. Some firms have combined batching and zoning into "wave" picking where each picker is responsible for SKUs in their zone for numerous orders. The benefit for these types of policies become apparent as the size of the warehouse increases, but zone picking requires secondary operations to consolidate orders from the different zones [7].

\subsection{Storage}

Storage policies assign SKUs to storage locations. The most common policy is random storage where SKUs are assigned randomly throughout the warehouse. The advantage is that random storage is easy to administer and may ease picker congestion, but generally it results in longer picker travel distance [3]. Volume-based storage (VBS) policies assign SKUs to locations near the pick-up/drop-off (P/D) point based on their picking volume [8] [9] [10] [11]. They are generally more effective at minimizing picker travel, but are information intensive and far more difficult to administer than random storage [10]. Similar to VBS, class-based storage (CBS) ranks SKUs according to pick activity then partitions the SKUs into several storage classes and randomly assigns them to warehouse locations within their respective storage class area. The storage class containing the highest volume SKUs is located nearest to the P/D point. The impetus of a CBS policy is to capitalize on the logic of the VBS policy, while eliminating the considerable administrative overhead [12]. Class-based storage with as few as three storage classes provides nearly the same savings as volume-based storage in an automated storage and retrieval systems [13] [14] [15] and in manual warehouses [16]. 


\subsection{Routing}

Routing policies determine the picking sequence of SKUs on the pick list. Using simple heuristics or optimal procedures, the goal of routing policies is to minimize the distance traveled by the picker. Optimal procedures offer the best solution, but may result in confusing routes [17]. Heuristics often yield near-optimal solutions while being easy to use [18] [19]. Traversal routing, where pickers must completely traverse the entire aisle once it is entered, is widely used in many warehouses because of its simplicity and provides good results when the pick density per picking aisle is high [19]. Another simple heuristic is return routing where a picker after picking all the items in a picking aisle returns back to the front aisle before proceeding to the next picking aisle. The combined heuristic uses both traversal and return routes to further reduce picker travel to produce near-optimal solutions [20] [21] [22] [23]. Vaughan and Petersen [24] developed a dynamic programming shortest path routing method to minimize the total picking distance in warehouses with multiple cross aisles.

\subsection{Layout}

The layout of the warehouse has been considered as a factor affecting order picking efficiency. Several issues have been researched from the alignment of the picking aisles with respect to the P/D point, the location of the P/D point, and the overall shape has also been taken into consideration as factors effecting order picking efficiency [25] [26] [27] [28]. Adding cross aisles to a warehouse layout allows greater flexibility in order picking routing and therefore provides shorter order picking travel distances [23] [24] [29] [30].

There has been research on the use of class-based storage and the placement of cross aisles. Rao and Adil [31] investigate class based storage and the number of aisles for a variety of pick list sizes, however, their work considers only a return routing policy via the use of a center cross aisle. Berglund and Batta [32] show analytical results that unequal cross aisles are superior to equally-spaced cross aisles. However, their results assume a center P/D point and use pick list sizes of only two to ten SKUs.

This study extends the prior research. First, this study evaluates even and uneven placement of cross aisles in a manual order picking warehouse with a corner P/D point and bin shelving. Second, this research compares class-based storage and random storage in a warehouse with no interior cross aisles or with two interior cross aisles. Third, this study uses the commonly used traversal routing policy. Lastly, this research examines the effect of order pick list size on the performance of cross aisle placement and storage polices and the interactions of these factors.

\section{Experimental Design}

The simulated warehouse shown in Figure 1 has ten picking aisles with front and back aisles. The P/D point is located in the left side of the front aisle. This warehouse is a manual-picking environment where picking carts are used to transport the picked SKUs. The picking aisles are two-sided so that picking can be done from both sides of the aisle without a significant change in position and also wide enough to allow twoway travel of picking carts. The capacity of the bin shelving warehouse is 1200 SKUs 


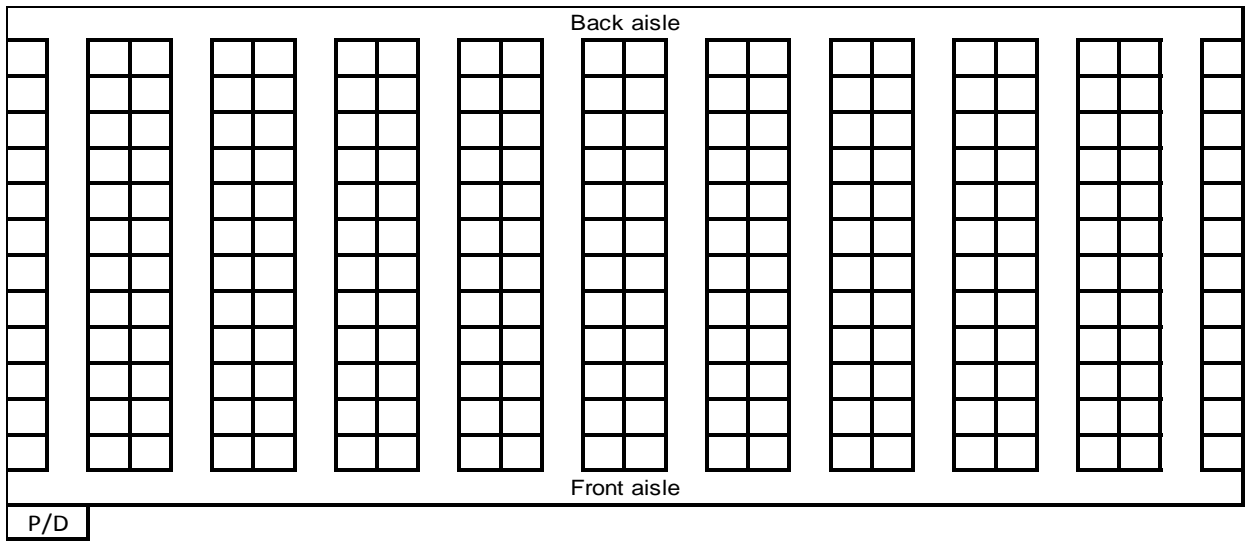

Figure 1. Basic layout with no cross aisles.

and each SKU is assigned to a single storage location. There are twelve bin facings on each side of a picking aisle and there are five storage slots per bin facing. Strict-order/ batch picking is used where a picker departs the P/D point to retrieve SKUs on the pick list and transports the SKUs back to the P/D point for order consolidation, packaging, and shipment. The picking carts are designed in a manner that maintains order integrity. This is commonly referred to as sort-while-picking. Total travel distance consisting of travel along the front and back aisles and travel within the picking aisles is collected for each simulation trial. The traversal routing heuristic is used for this experiment and can achieve close to optimal results when the pick density is high [10] [33]. The picker will access a picking aisle as far as the farthest SKU location and either traverse the entire picking aisle or use a cross aisle for access to the next picking aisle.

To utilize class-based storage, SKUs must be ranked according to their total picking volume. The ranked SKU list is partitioned into several classes, where the high volume SKUs are placed in one class and the lower volume SKUs are placed in additional classes. SKUs are then randomly assigned to storage locations within their respective class storage area [16]. One design parameter that a warehouse manager must select when using class-based storage policies is the class partition strategy. For this experiment a partition strategy for a three class system of 20-30-50 will be used as it was found to be effective at reducing picker travel [16].

The purpose of this research is to examine the interactions between cross aisle placement and storage policies on order picking efficiency as shown in the experimental design of Table 1. For the cross aisle placement Figure 2 shows an even cross aisle placement (E) of four facings (4-4-4) between each cross aisle. Figure 3 shows an uneven cross aisle placement $(\mathrm{U})$ of three facings between the first three cross aisles and six facings (3-3-6) between the last two cross aisles. Figure 4 and Figure 5 show across-aisle (A) and within-aisle (W) storage policies. Petersen and Schmenner [10] showed that pick list size affects the performance of storage and routing policies. Therefore, three levels of pick list sizes (PLS) are considered: 5 SKUs, 15 SKUs, and 25 SKUs. Results for additional pick list sizes can be easily extrapolated from the results presented.

There are 30 replications or pick lists generated for each pick list size. For a given pick list, SKUs are randomly generated using an 80/20 SKU demand distribution where 


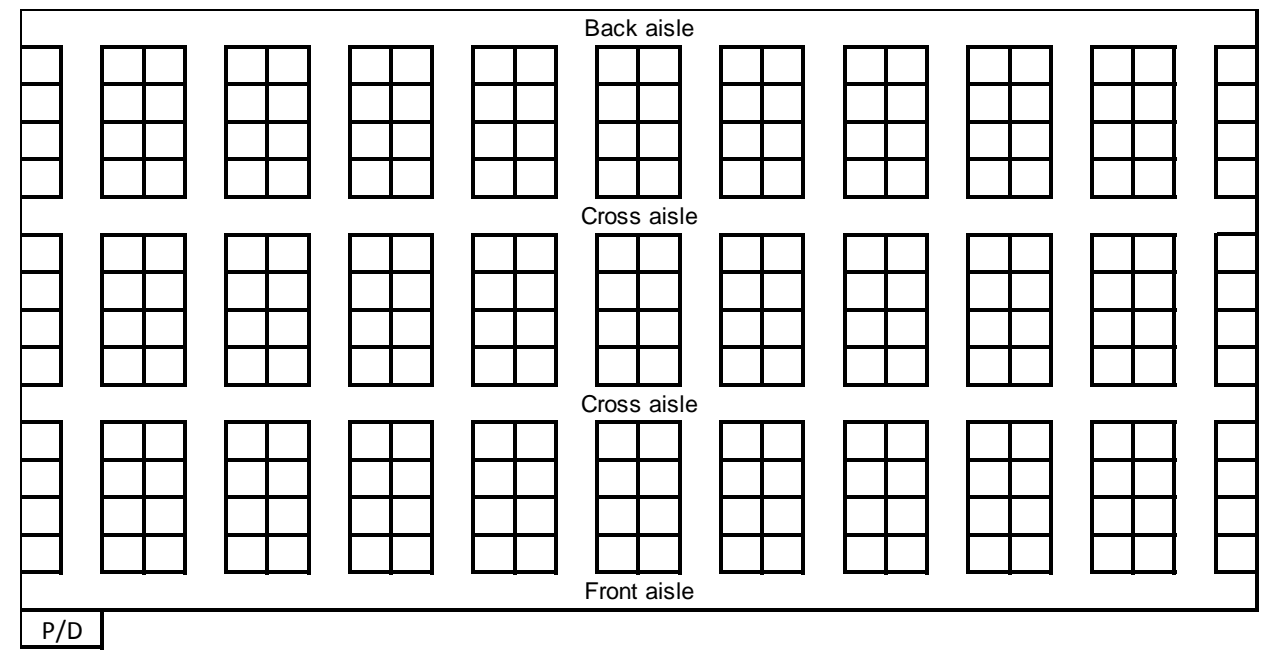

Figure 2. Layout with even cross aisle placement.

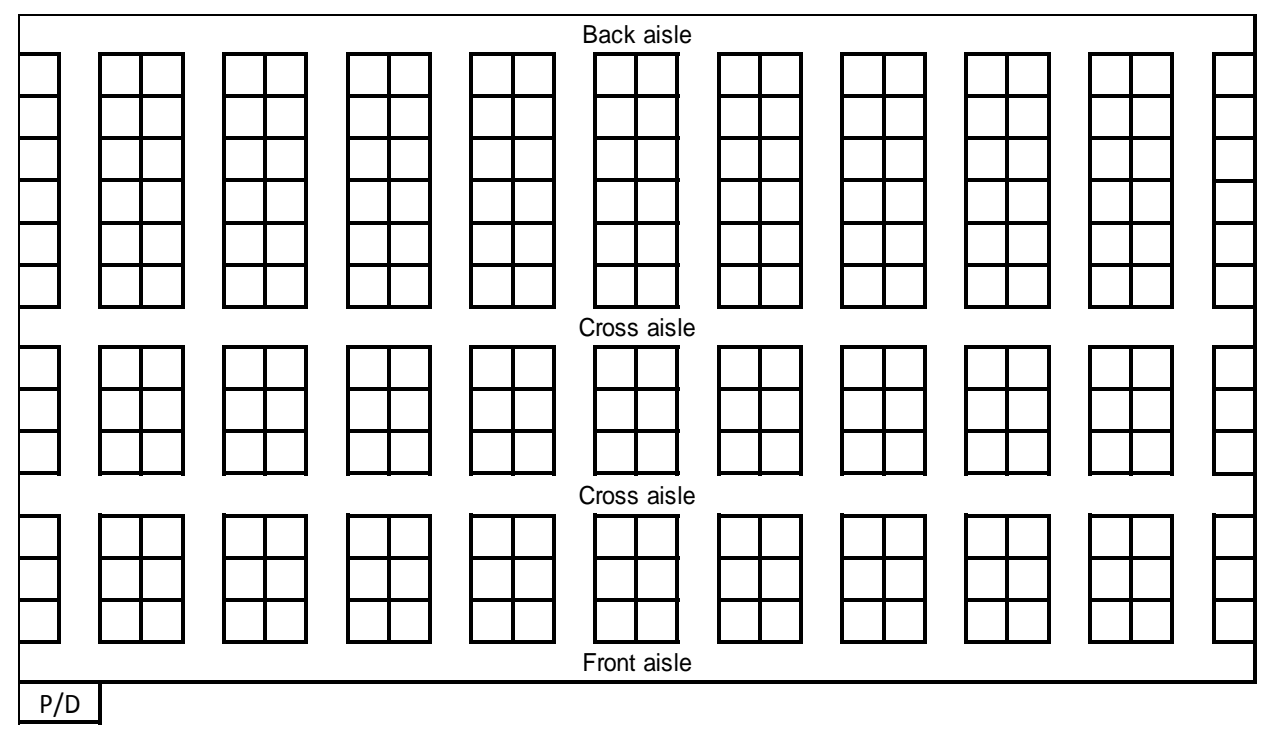

Figure 3. Layout with uneven cross aisle placement.

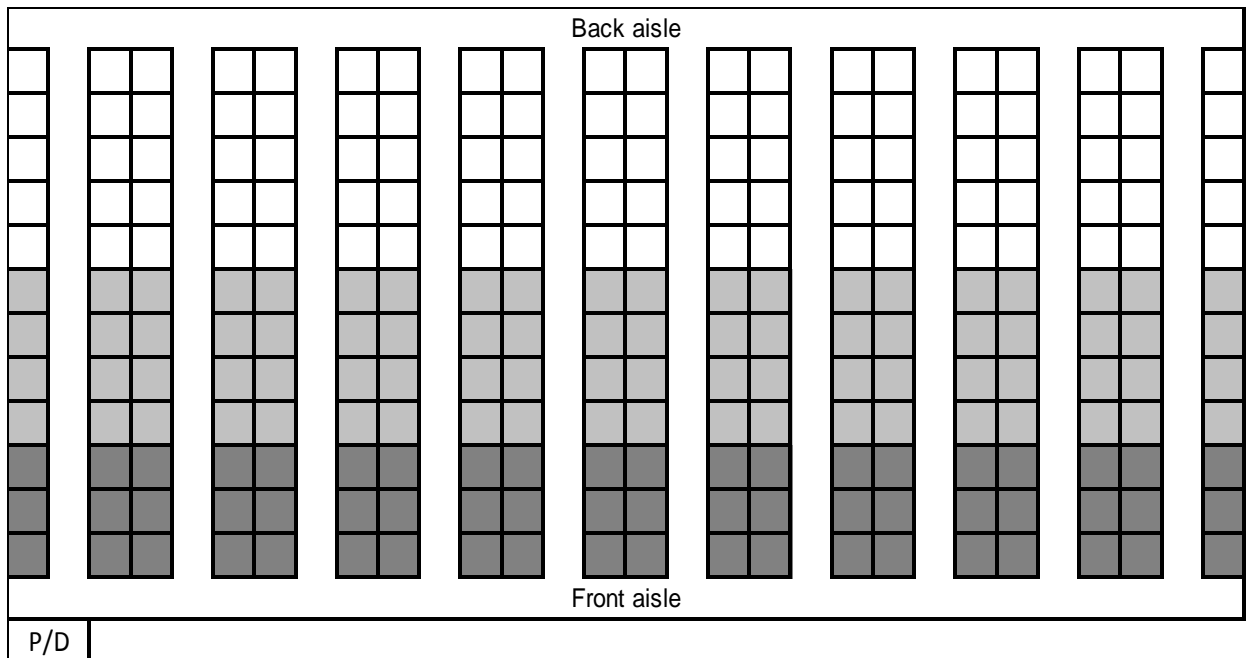

Figure 4. Layout with across-aisle storage policy. 


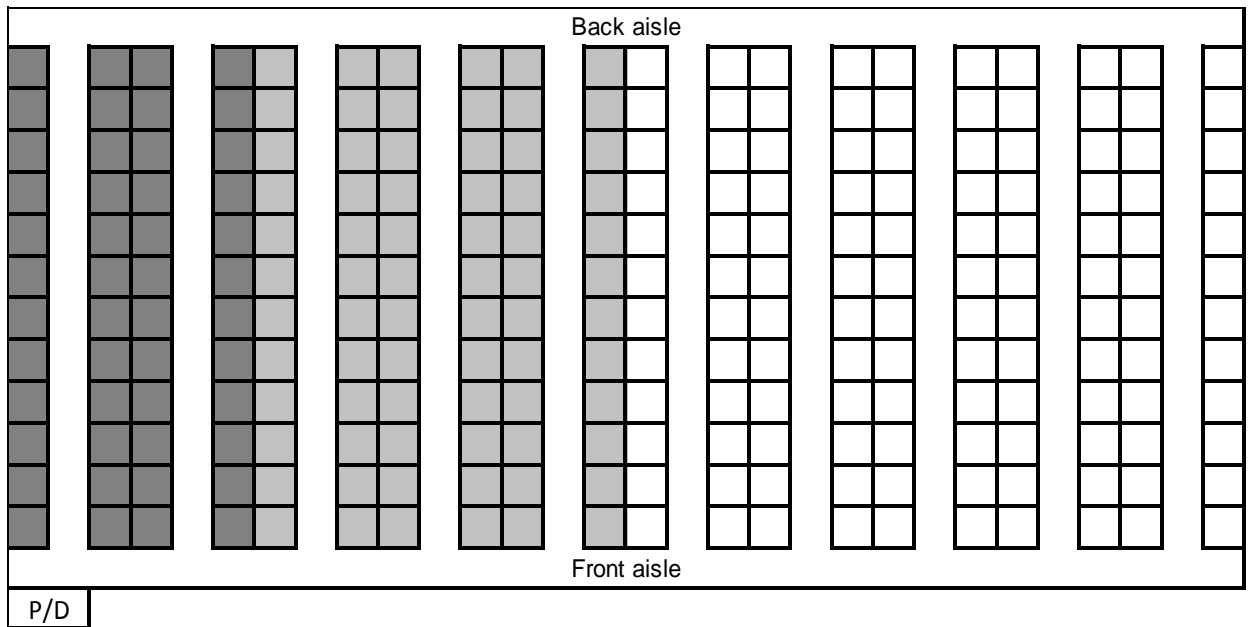

Figure 5. Layout with within-aisle storage policy.

Table 1. Experimental design.

\begin{tabular}{ccc}
\hline Layout & Storage Policy & Pick List Size \\
\hline Basic (B) & Random (R) & 5 \\
Even cross aisles (E) & Across-aisle (A) & 15 \\
Uneven cross aisles (U) & Within-aisle (W) & 25 \\
\hline
\end{tabular}

the top $20 \%$ of the SKUs account for $80 \%$ of the demand by volume. The total travel distance for the order picker to complete a given pick list is the performance measure

\section{Results}

The results of the simulation experiment are presented in Table 2. A full-factorial analysis of variance (ANOVA) showed statistical significance $(p$-values $<0.001)$ for the model, factors and interactions. The layout either with or without cross aisles has little effect as the PLS increases with both random and within-aisle storage, but not with across-aisle storage. Therefore, if across-aisle storage is used, then any cross aisle configuration is sufficient to reduce picker travel.

From the results, post-hoc t-tests were conducted with all results significant ( $p$-value $<0.01$ ) with the following exceptions. The even cross aisle layout (E) and uneven cross aisle layout $(\mathrm{U})$ showed no statistical difference which is primarily due to the use of traversal routing. The placement of the uneven cross aisles in a 3-3-6 layout may also been a contributing factor and is worthy of future study. The across-aisle storage (A) was also not statistical different from random storage (R) in the basic layout (B) with no cross aisles due to traversal routing.

There are several observations from Figure 6 which shows several notable interactions between layout-storage combinations. In warehouses with random storage the use of cross aisles (ER) does result in statistically less travel distance than warehouse with no cross aisles (BR). This result follows the prior research that the use of cross aisles results in less picker travel [22] [23] [24]. However, this difference dissipates as the PLS approaches 25 SKUs. 


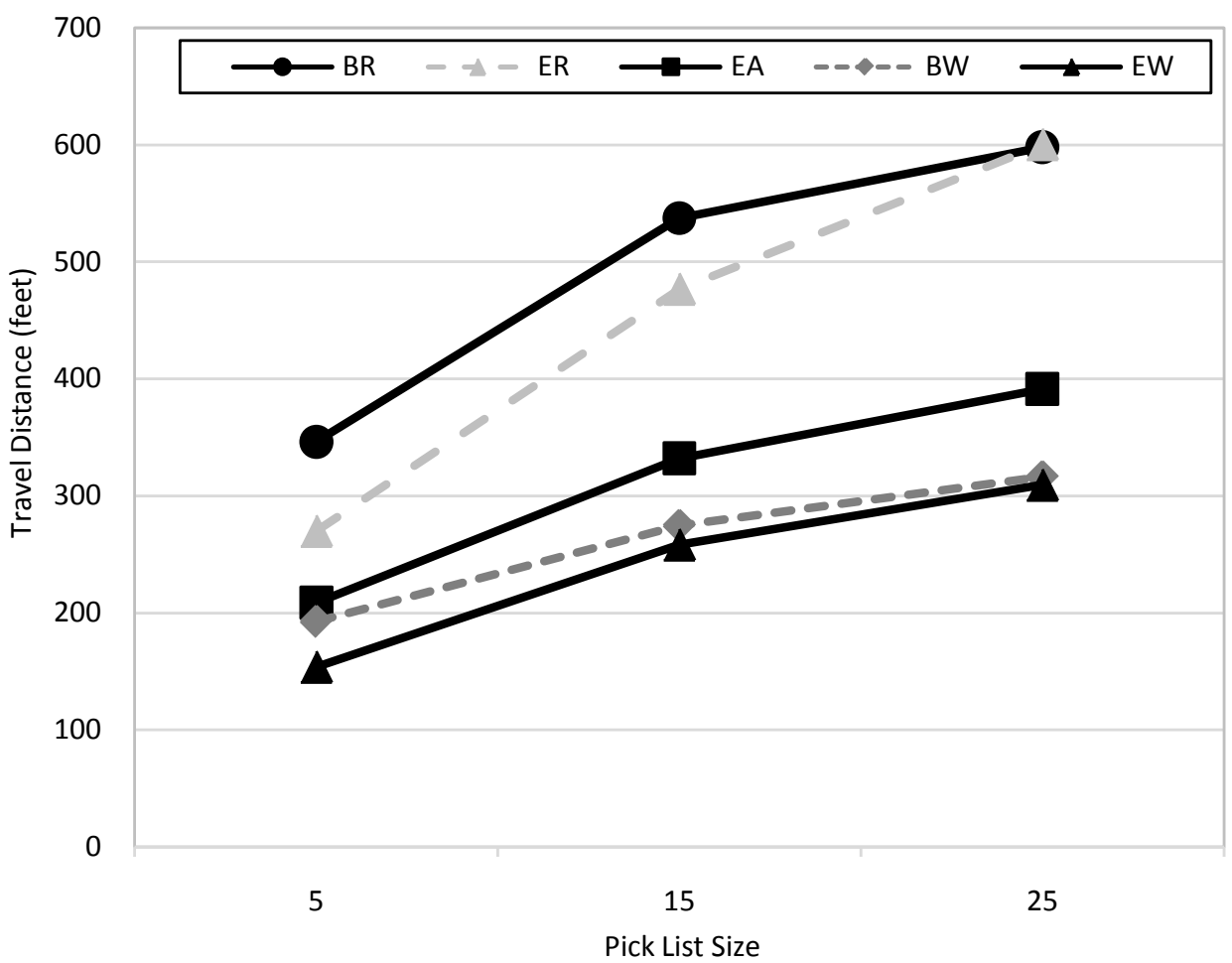

Figure 6. Layout-storage combinations by pick list size.

Table 2. Simulation results (picker travel in feet).

\begin{tabular}{cccccccccc}
\hline PLS & BR & BA & BW & ER & EA & EW & UR & UA & UW \\
\hline 5 & 346.2 & 338.9 & 192.8 & 270.1 & 208.7 & 153.9 & 272.0 & 206.2 & 155.4 \\
15 & 537.3 & 532.5 & 274.8 & 476.8 & 332.1 & 258.3 & 478.1 & 328.8 & 258.4 \\
25 & 598.0 & 594.5 & 316.4 & 600.4 & 391.4 & 309.4 & 600.1 & 391.3 & 308.6
\end{tabular}

Note: First letter denotes layout; second letter denotes storage policy.

Second, across-aisle storage in a warehouse with evenly spaced cross aisles (EA) performs statistically better than random storage with evenly spaced cross aisles (ER). Previous research has found that across-aisle storage reduces picker travel compared to random storage but most of that research used optimal routing [16]. In this paper with traversal routing each aisle must be completely traversed unless there is a cross aisle that allows access to the next picking aisle. Since across-aisle storage assigns the SKUs with the largest pick volumes closest to the front aisle most aisles would only have to be traversed to one of the cross aisles instead of having to traverse the entire picking aisle. Simply put, cross aisles utilize the potential benefit provided with across-aisle storage policies.

Third, within-aisle storage (EW) performs statistically better than across-aisle (EA) and random storage. This is in line with the findings of Petersen, et al. [16]. More important is that within-aisle storage with no cross aisles (BW) performs statistically better than across-aisle storage with cross aisles (EA). The use of cross aisles does statistically reduce picker travel for within-aisle storage compared to warehouses with no cross aisles. 
Lastly, the results and Figure 6 show that pick list size (PLS) does have an effect on the performance of storage policies and the use of cross aisles. A larger PLS increases the pick density and therefore diminishes the savings gained by cross aisles and storage assignment policies. The magnitude of these savings would decrease if the 80/20 SKU demand distribution becomes less skewed to a 50/30 SKU demand distribution.

\section{Conclusions}

This paper evaluated cross aisle placement in a manual warehouse with class-based storage. The results show that even and uneven cross aisle placement does not statistically differ and that the addition of cross aisles does significantly reduce picker travel as has been shown in previous research. As in warehouses without cross aisles, within-aisle storage results in significantly less picker travel than across-aisle and random storage in a warehouse with cross aisles. In fact, within-aisle storage resulted in less picker travel than the addition of cross aisles in a random or across-aisle storage warehouse. All of these results held for small, medium, and large pick list sizes.

The drawbacks to class-based storage are that it can result in increased picker congestion which may offset some of the picker time savings. Also the use of cross aisles could increase the possibility of picker accidents if pickers are not careful at cross aisle and picking aisle intersections. A limitation of this research is that only one uneven cross aisle placement strategy was considered, but this research provides an avenue for future research to evaluate other uneven cross aisle placement strategies in manual warehouses.

\section{References}

[1] Bozer, Y.A., Tanchoco, J., Tompkins, J.A. and White, J.A. (2010) Facilities Planning. John Wiley \& Sons, Inc., Hoboken.

[2] Coyle, J.J., Bardi, E.J. and Langley, C.J. (2003) The Management of Business Logistics: A Supply Chain Perspective. 7th Edition, South-Western, Mason, Ohio.

[3] Frazelle, E. (2002) World-Class Warehousing and Material Handling. McGraw-Hill, New York.

[4] Gibson, D.R. and Sharp, G.P. (1992) Order Batching Procedures. European Journal of Operational Research, 58, 57-67. https://doi.org/10.1016/0377-2217(92)90235-2

[5] Rosenwein, M.B. (1996) A Comparison of Heuristics for the Problem of Batching Orders for Warehouse Selection. International Journal of Production Research, 34, 657-664. https://doi.org/10.1080/00207549608904926

[6] De Koster, M.B.M., Van der Poort, E.S. and Wolters, M. (1999) Efficient Order Batching Methods in Warehouses. International Journal of Production Research, 37, 1479-1504. https://doi.org/10.1080/002075499191094

[7] Petersen II, C.G. (2000) An Evaluation of Order Picking Policies for Mail Order Companies. Production and Operations Management, 9, 319-335.

[8] Jarvis, J.M. and McDowell, E.D. (1991) Optimal Product Layout in an Order Picking Warehouse. IIE Transactions, 23, 93-102. https://doi.org/10.1080/07408179108963844

[9] Caron, F., Marchet, G. and Perego, A. (1998) Routing Policies and COI-Based Storage Policies in Picker-to-Part Systems. International Journal of Production Research, 36, 713-732. https://doi.org/10.1080/002075498193651

[10] Petersen, C.G. and Schmenner, R.W. (1999) An Evaluation of Routing and Volume-Based 
Storage Policies in an Order Picking Operation. Decision Sciences, 30, 481-501. https://doi.org/10.1111/j.1540-5915.1999.tb01619.x

[11] Jane, C.C. (2000) Storage Location Assignment in a Distribution Center. International Journal of Physical Distribution \& Logistics Management, 30, 55-71. https://doi.org/10.1108/09600030010307984

[12] Larson, T.N., March, H. and Kusiak, A. (1997) A Heuristic Approach to Warehouse Layout with Class-Based Storage. IIE Transactions, 29, 337-348. https://doi.org/10.1080/07408179708966339

[13] Hausman, W.H., Schwarz, L.B. and Graves, S.C. (1976) Optimal Storage Assignment in Automatic Warehousing Systems. Management Science, 22, 629-638. https://doi.org/10.1287/mnsc.22.6.629

[14] Rosenblatt, M.J. and Eynan, A. (1989) Deriving the Optimal Boundaries for Class-based Automatic Storage/Retrieval Systems. Management Science, 35, 1519-1524. https://doi.org/10.1287/mnsc.35.12.1519

[15] Eynan, A. and Rosenblatt, M.J. (1994) Establishing Zones in Single-Command Class-based Rectangular AS/RS. IIE Transactions, 26, 38-46. https://doi.org/10.1080/07408179408966583

[16] Petersen, C.G., Aase, G.R. and Heiser, D.R. (2004) Improving Order Picking Performance through the Implementation of Class-Based Storage. International Journal of Physical Distribution and Logistics Management, 34, 534-544.

http://dx.doi.org/10.1108/09600030410552230

[17] Ratliff, H.D. and Rosenthal, A.S. (1983) Order-Picking in a Rectangular Warehouse: A Solvable Case of the Traveling Salesman Problem. Operations Research, 31, 507-521. http://dx.doi.org/10.1287/opre.31.3.507

[18] Hall, R.W. (1993) Distance Approximations for Routing Manual Pickers in a Warehouse. IIE Transactions, 25, 76-87. http://dx.doi.org/10.1080/07408179308964306

[19] Petersen, C.G. (1997) An Evaluation of Order Picking Routing Policies. International Journal of Operations \& Production Management, 17, 1096-1111. http://dx.doi.org/10.1108/01443579710177860

[20] De Koster, R. and Van der Poort, E. (1998) Routing Orderpickers in a Warehouse: A Comparison between Optimal and Heuristics Solutions. IIE Transactions, 30, 469-480. http://dx.doi.org/10.1080/07408179808966487

[21] Petersen, C.G. (1999) The Impact of Routing and Storage Policies on Warehouse Efficiency. International Journal of Operations \& Production Management, 19, 1053-1064. http://dx.doi.org/10.1108/01443579910287073

[22] Roodbergen, K.J. and De Koster, R.A. (2001) Routing Order Pickers in a Warehouse with a Middle Aisle. European Journal of Operational Research, 133, 32-43. http://dx.doi.org/10.1016/S0377-2217(00)00177-6

[23] Roodbergen, K.J. and De Koster, R.A. (2001) Routing Methods for Warehouses with Multiple Cross Aisles. International Journal of Production Research, 39, 1865-1883. http://dx.doi.org/10.1080/00207540110028128

[24] Vaughan, T.S. and Petersen, C.G. (1999) The Effect of Warehouse Cross Aisles on Order Picking Efficiency. International Journal of Operations Research, 37, 881-897. http://dx.doi.org/10.1080/002075499191580

[25] Bassan, Y., Roll, Y. and Rosenblatt, M.J. (1980) Internal Layout Design of a Warehouse. AIIE Transactions, 12, 317-322. http://dx.doi.org/10.1080/05695558008974523

[26] Petersen, C.G. (2002) Considerations in Order Picking Zone Configuration. International Journal of Operations \& Production Management, 22, 793-805. http://dx.doi.org/10.1108/01443570210433553 
[27] Gue, K.R. and Meller, R.D. (2009) Aisle Configurations for Unit-Load Warehouses. IIE Transactions, 41, 171-182. http://dx.doi.org/10.1080/07408170802112726

[28] Pohl, L.M., Meller, R.D. and Gue, K.R. (2011) Turnover-Based Storage in Non-Traditional Unit-Load Warehouse Designs. IIE Transactions, 43, 703-721. http://dx.doi.org/10.1080/0740817X.2010.549098

[29] Ben-Mahmud, Y. (1987) The Effect of Warehouse Layout on Order Picking Efficiency. Unpublished M.S. Thesis, Oregon State University, Corvallis, OR.

[30] Caron, F., Marchet, G. and Perego, A. (2000) Optimal Layout in Low-Level Picker-to-Part Systems. International Journal of Production Research, 38, 101-117. http://dx.doi.org/10.1080/002075400189608

[31] Rao, S. and Adil, G.K. (2013) Optimal Class Boundaries, Number of Aisles, and Pick List Size for Low-Level Order Picking Systems. IIE Transactions, 45, 1309-1332. http://dx.doi.org/10.1080/0740817X.2013.772691

[32] Berglund, P. and Batta, R. (2012) Optimal Placement of Warehouse Cross Aisles in a Picker-to-Part Warehouse with Class-Based Storage. IIE Transactions, 44, 107-120. http://dx.doi.org/10.1080/0740817X.2011.578608

[33] Petersen, C.G. and Aase, G.R. (2004) A Comparison of Picking, Storage, and Routing Policies in Manual Order Picking. International Journal of Production Economics, 92, 11-19. http://dx.doi.org/10.1016/j.ijpe.2003.09.006

\section{Submit or recommend next manuscript to SCIRP and we will provide best service} for you:

Accepting pre-submission inquiries through Email, Facebook, LinkedIn, Twitter, etc. A wide selection of journals (inclusive of 9 subjects, more than 200 journals)

Providing 24-hour high-quality service

User-friendly online submission system

Fair and swift peer-review system

Efficient typesetting and proofreading procedure

Display of the result of downloads and visits, as well as the number of cited articles

Maximum dissemination of your research work

Submit your manuscript at: http://papersubmission.scirp.org/

Or contact ojbm@scirp.org 